\title{
Influence of light and its temperature on solar photovoltaic panels
}

\author{
Xin $\mathrm{Hou}^{1 *}$, Daoyuan $\mathrm{Wen}^{2}$, Fangqin $\mathrm{Li}^{1}$, Chuang $\mathrm{Ma}^{1}$, Xiaotong Zhang ${ }^{1}$, Haijun Feng ${ }^{1}$, Jianxing Ren ${ }^{1}$ \\ ${ }^{1}$ School of Energy and Mechanical Engineering, Shanghai University of Electric Power, Shanghai 200090, China \\ ${ }^{2}$ Department of International Environmental Engineering The University of Kitakyushu, Fukuoka,Japan
}

\begin{abstract}
Due to the increasingly limited conventional energy and increasing environmental problems, the photovoltaic industry is receiving more and more attention from all over the world. China's solar photovoltaic industry has driven rapid development in electricity prices. Photovoltaic power generation is affected by light intensity and photovoltaic panel temperature. In this paper, the effects of light intensity and photovoltaic panel temperature on photovoltaic panel power generation are discussed.
\end{abstract}

\section{Introduction}

With the depletion of non-renewable resources such as oil, coal, natural gas and the increasing air pollution, solar photovoltaic power generation as a new, clean and renewable energy source, highlights its important position in the global energy field ${ }^{[1]}$.

China's solar energy resources are even more abundant. The division of solar energy resources in the country is shown in Table $1^{[2]}$, which has absolute advantages in solar energy resources compared with countries such as Europe and Japan. In most areas, the annual sunshine hours are long, and there are many areas suitable for photovoltaic power generation. Rich lighting resources is a prerequisite for China to vigorously develop the photovoltaic industry.

Table 1 National Solar Resource Area Division

\begin{tabular}{|cccc|}
\hline Grade & $\begin{array}{c}\text { Annual total } \\
\text { radiation }\left(\mathbf{M J} / \mathbf{m}^{\mathbf{2}}\right)\end{array}$ & $\begin{array}{c}\text { Annual sunshine } \\
\text { hours } \mathbf{( h / \mathbf { a } )}\end{array}$ & Main area \\
\hline I & $6690-8360$ & $3200-3300$ & $\begin{array}{c}\text { Western Qinghai, western Tibet, northern Ningxia, northern } \\
\text { Gansu, southeastern Xinjiang }\end{array}$ \\
\hline II & $5852-6690$ & $3000-3200$ & $\begin{array}{c}\text { Northwestern Hebei, northwestern Shaanxi, southern Inner } \\
\text { Mongolia, southern Xinjiang, southern Ningxia, central } \\
\text { Gansu, eastern Qinghai }\end{array}$ \\
\hline III & $5016-5822$ & $2200-3000$ & $\begin{array}{c}\text { Southeast of Hebei, southwestern Shanxi, northern Xinjiang, } \\
\text { northwestern Shaanxi, southeastern Gansu, southern } \\
\text { Guangdong, northern Jiangsu, Jilin, Shandong }\end{array}$ \\
\hline IV & $4180-5016$ & $1400-2200$ & $\begin{array}{c}\text { Northern Fujian, Northern Guangdong, Southwest Shaanxi, } \\
\text { Southern Anhui, Hunan, Guangxi, Jiangxi, Zhejiang, Hubei }\end{array}$ \\
\hline V & $3344-4180$ & $1000-1400$ & Most of Sichuan, Guizhou \\
\hline
\end{tabular}

After decades of development, China's photovoltaic power generation industry has quickly entered the right track, which has played an important practical significance for the sustainable long-term development of the electric power industry. According to statistics, at the end of 2018, the total installed capacity of domestic photovoltaic power generation systems is about $143 \mathrm{GW}$, and the number of enterprises specializing in the production of solar cells is also increasing, and the production capacity of solar cells is also developing by leaps and bounds ${ }^{[3]}$. The installed capacity of photovoltaics and the cumulative installed capacity of photovoltaic power generation from 2013 to 2018 are shown in Figure 1, Figure 2 (data source from network consolidation).

However, since the output of the photovoltaic cell has strong nonlinearity, and the nonlinearity is affected by the external environment (including light intensity, temperature, etc.), the output power of the photovoltaic cell is liable to change, and the actual use efficiency is limited, so the light is limited. Research on the influence of intensity and temperature on the output characteristics of photovoltaic cells has become an important topic ${ }^{[4-5]}$.

\footnotetext{
* Corresponding author: 7192098@qq.com
} 

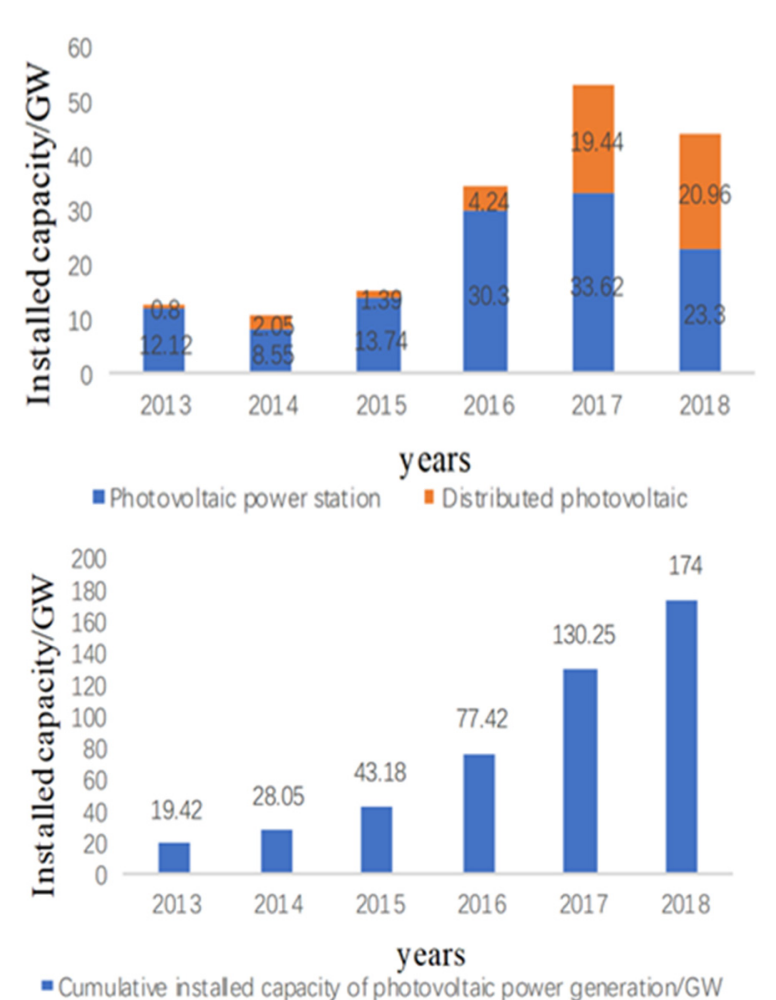

Figure 1 PV new installed capacity

Figure 2 cumulative installed capacity of photovoltaic power generation

\section{The impact of sunshine changes on photovoltaic panels}

\subsection{Influencing factors of light intensity}

Influence of meteorological factors. Meteorological factors such as clouds, fog, dew, rain, have a great influence on the illumination, and the changes are frequent.

Sunshine azimuth influence. One is the azimuth affected by the Earth's rotation, and the other is the azimuth affected by the Earth's revolution. This article explores the changes in sunshine that are affected by the Earth's rotation, that is, changes over time ${ }^{[6]}$.

The earth rotates from west to east every 360 degrees for one week. This paper does not consider the influence of latitude and geographical factors. When the sun rises from the eastern horizon, the azimuth of sunshine is $\alpha=90^{\circ}$; the sun's azimuth when the sun goes directly to the local meridian $\alpha=0^{\circ}$; when the afternoon sun falls from the western horizon, the azimuth of sunshine is $\alpha=$ $90^{\circ}$. The time difference from rising to falling is called sunshine time. In the sunshine time, the range of $\alpha$ varies from $90^{\circ}$ to $0^{\circ}$ to $90^{\circ}$, for a total of $180^{\circ}$. The spatial orientation of the $\alpha$ change trajectory is shown in Fig. $3^{[7]}$.

In the $1 \mathrm{~d}$ sunshine hours, the sunshine azimuth angle $\alpha$ changes by $180^{\circ}$, and the sunshine intensity changes correspondingly with the change of $\alpha$. At noon $\alpha=0^{\circ}$, the sunshine is the strongest, and in the morning or afternoon, the daylight increases as $\alpha$ increases.

\subsection{Photoelectric output standard value [8]}

The absolute value of the photoelectric output refers to the output power $\mathrm{P}(\mathrm{kW})$ of the photovoltaic device or the daily power generation amount $\mathrm{E}\left(\mathrm{kW}^{*} \mathrm{~h}\right)$. The absolute values of sunshine intensity and photoelectric output are affected by meteorological factors and sunshine azimuth $\alpha$, and the change is impermanent and inconvenient to study. Therefore, a relative amount is introduced as a reference amount for research. Based on the maximum value of the noon sunshine intensity, the standard value (reference amount) of the light intensity at this time is set to 1 , and the sunshine is weakest in the morning sunrise and evening sunset, regardless of the specific value of the light intensity at this time. Its standard value is 0 . Similarly, when the noon sunshine is the strongest, the photoelectric output is the largest. The standard value of the photoelectric output is set to 1 . The morning and evening sunsets are the weakest. When the absolute value of the photoelectric output is 0 , the photoelectric is set. The output has a value of 0 . In this way, the standard value of the photoelectric output and the standard value of the sunshine intensity are completely synchronized.

Regardless of the influence of meteorological change factors, $\cos \alpha$ is used to simulate the sunshine intensity standard value and the photoelectric output standard value. In the $1 \mathrm{~d}$ sunshine time, observe whether the standard value of the photoelectric output at other times (corresponding azimuth $\alpha$ ) is $\operatorname{Cos} \alpha$ is consistent. The photoelectric output standard value simulation value is shown in Figure 3.

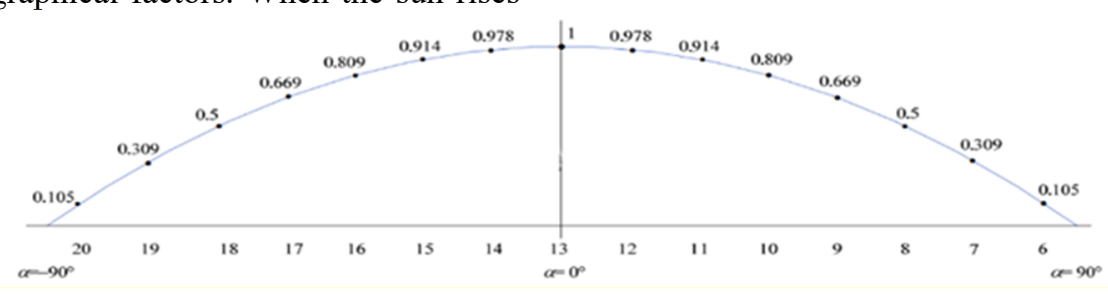

Figure 3 Xiazhi Photoelectric Output Standard Value

According to the simulation of sunshine changes within one day, the simulation shows the influence of sunshine on the output power of photovoltaic power generation. Under the same conditions, the enhanced light intensity can enhance the output power of photovoltaic panels. In order to obtain more illumination, it is necessary to set the photovoltaic panels. Automatic 
adjustment device to keep the photovoltaic panel exposed to maximum illumination.

\section{The effect of temperature on solar cellsatalytic properties of perovskite materials}

Figure 4 shows the IV of a single crystal silicon cell at different temperatures. As the temperature increases, the ISC changes are not obvious and the VOC changes greatly ${ }^{[9]}$; this is because the current is mainly related to the light intensity, and the voltage is mainly affected by the temperature. The device band width is determined [10].

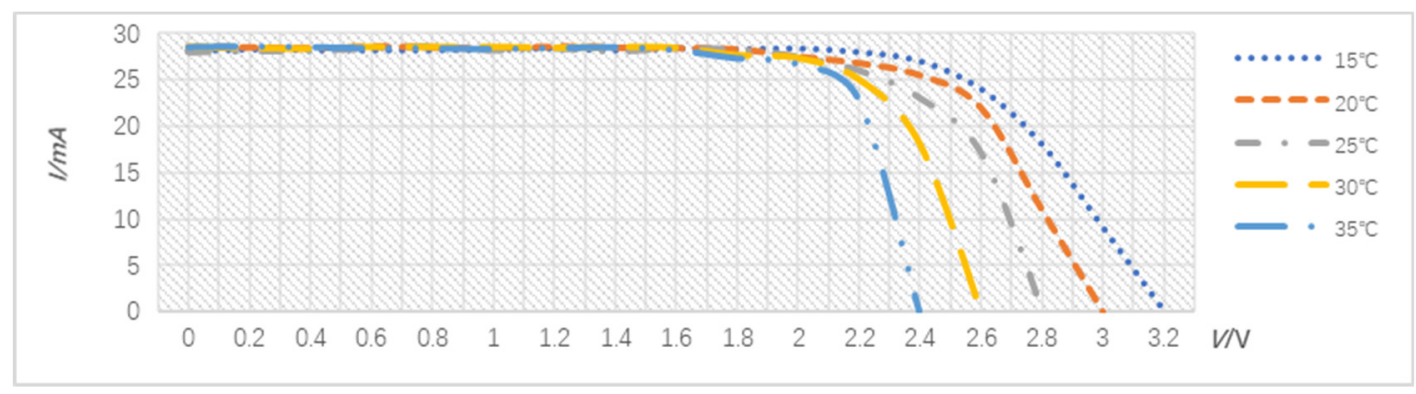

Figure $4 \mathrm{I}-\mathrm{V}$ characteristic curve of single crystal silicon cell at different temperatures

\section{Conclusion}

Solar energy is an ideal alternative energy source, and it is inexhaustible and inexhaustible. It is necessary to continuously research solar power generation technology. In summary, the output power of the solar photovoltaic panel needs to be adjusted to the orientation of the solar photovoltaic panel, and the light intensity tracking technology is used to ensure that the solar panel maintains maximum efficiency in one day. Since the temperature has a great influence on the power generation efficiency, the solar panel is cooled while ensuring the maximum efficiency of the solar panel to ensure that it operates in an optimal working condition, and the temperature of the solar photovoltaic panel toward the integrated solar panel can also be adjusted. We should adjust to ensure the output power of the solar panel, balance the working temperature with the acceptance of solar radiation, and make full use of solar energy for the benefit of mankind.

\section{References}

1. YANG Sijun, PAN Jingying. Research Progress in the Application of Photovoltaic Power Generation[J]. Volkswagen Technology, 2008(8).

2. Liu Shuang. Solar Energy Utilization and Solar Building Development[J]. Science and Technology Achievements, 2007(6):39-40.

3. Shan Yiguo, Han Xinyang, Tan Xiandong, et al. China's "13th Five-Year Plan" and Medium- and
Long-Term Power Demand Research $[\mathrm{J}]$. China Electric Power, 2015, 48(1): 6-10.

4. $\mathrm{Xu}$ Yongfeng, Li Ming, Wang Liuling, et al. Influence of concentrated light intensity on output performance of photovoltaic arrays[J]. Acta Phys. Sinica, 2009, 58(11): 8067-8076.

5. Kim J H, Moon, Kook Joo, et al. Effects of various light-intensity and temperature environments on the photovoltaic performance of dye-sensitized solar cells[J]. Solar Energy, 2015, 113:251-257.

6. Dai Qian, Duan Shanxu, Cai Tao, et al. Short-term non-irradiance power generation prediction model for photovoltaic systems based on weather type clustering identification $[\mathrm{J}]$. Proceedings of the CSEE, 2011, 31(34):28-35.

7. Huang Wei, Zhang Tian, Han Xiangrong, et al. Sunlight intensity time function and meteorological factors affecting photovoltaic power generation[J]. Power System Technology, 2014, 38(10): 2789-2793.

8. Dong Lei, Zhou Wenping, Zhang Pei, et al. Short-term Probability Prediction of Photovoltaic Generation Based on Dynamic Bayesian Network[J]. Proceedings of the CSEE, 2013, 33(s1):38-45.

9. Xiao Lixian, He Yongtai, Peng Yuehong, et al. Theoretical and Experimental Study on the Influence of Temperature on the Conversion Characteristics of Photovoltaic Cells[J]. Journal of Electric Materials and Measurement, 2014, 51(17): 62-66.

10. Zhou W, Hongxing Yang, Zhaohong Fang. A novel model for photovoltaic array performance prediction[J]. Appl Energy, 2007, 84(12):1187-1198. 